\title{
Configurational meaning and conceptual shifts in design
}

\section{John Peponis \\ Sonit Bafna}

\author{
School of Architecture, Georgia Institute of \\ Technology, Atlanta, Georgia, United States of \\ America (authors' e-mail addresses: John.Peponis@ \\ coa.gatech.edu - Corresponding Author; \\ sonit.bafna@coa.gatech.edu)
}

\section{Saleem Mokbel Dahabreh Fehmi Dogan}

Architecture and Engineering, University of Jordan

Amman, Jordan; Architecture, Izmir Institute of

Technology, Turkey (authors' e-mail addresses:

saleem.dahabreh@ju.edu.jo; fehmidogan@gmail.

com)

Configuration is defined as the entailment of a set of co-present relationships embedded in a design, such that we can read a logic into the way in which the design is put together. We discuss conceptual shifts during design with particular emphasis on the designer's understanding of what kind of configuration the particular design is. The design for the Unitarian Church offers an historical example of such shifts, authorised by Kahn's own post-rationalisation of the design process. We subsequently construct a formal computational experiment where the generation, description and re-conceptualisation of designs is rendered entirely discursive. The experiment serves to clarify the nature of conceptual shifts in actual design, and the reasons why a reading of such shifts cannot be based on discursive evidence only but necessarily requires us to engage presentational forms of symbolisation as well. Our examples demonstrate how a conceptual shift within a particular design can lead to the discovery of a new potential design world. In the historical case, the conceptualisation of a new design world remains implicit and inadequately specified. But the theoretical experiment allows us to make explicit how geometrically similar configurations that arise from the application of one set of generative rules may possess systematic but entirely unanticipated perceptual properties, subsequently incorporated in new generative rules. 
Induction infers a rule. Now, the belief of a rule is a habit. That a habit is a rule active in us, is evident. ... Induction, therefore, is the logical formula which expresses the physiological process of formation of a habit. Hypothesis substitutes, for a complicated tangle of predicates attached to one subject, a single conception. Now, there is a peculiar sensation belonging to the act of thinking that each of these predicates inheres in the subject. In hypothetic inference this complicated feeling so produced is replaced by a single feeling of greater intensity, that belonging to the act of thinking the hypothetic conclusion.... We may say, therefore, that hypothesis produces the sensuous element of thought, and induction the habitual element.

C. S. Peirce, 'Deduction, induction and hypothesis', The popularscience monthly, 13 (1878), pp. 481-2.

\section{Configuration and imaginative attention in architectural design}

This paper discusses conceptualisation and conceptual shifts with a bearing on a particular kind of attention elicited by buildings: imaginative attention applied to the appreciation of built form. Thus, we begin with a brief introduction of what we mean by imaginative attention and how it features in the context of design thinking. Herbert Simon defined design by suggesting that it is concerned with how things ought to be in order to attain goals and to function. ${ }^{1}$ In the case of architecture, the goals of design are usually set by the charge that the client gives to the architect, and more fully described in the building programme. Architects often introduce additional goals, including stylistic preferences, per- sonal design idioms or the desire to situate themselves within a design tradition. ${ }^{2}$ A design is typically evaluated as to whether it incorporates all the specifications of the programme; takes into account state of the art professional knowledge about buildings of a certain function-type, such as a school or a hospital; responds to relevant criteria of performance, for example creating a comfortable environment, or operating within specified cost limits over time; and conforms to, or extends, a prior understanding of styles and compositional languages.

The degree to which functional aims and criteria are all equally explicit or amenable to objective evaluation is open to discussion. House design, for example, often takes for granted cultural norms and expectations that are not stated in the brief; or, it responds critically to past social conventions in order to articulate emerging social identities and models of everyday life. ${ }^{3}$ Confronted with other kinds of buildings, architects must often decide which among competing sets of design principles is most applicable. In office design for example, different client organisations may have different sets of requirements regarding the importance of privacy, the kinds of interactions or collaborations that must be supported by design, or the manner in which space is allocated and used. ${ }^{4}$ But, with the caveat that articulating applicable functional criteria and goals is not always straightforward, Simon's phrase succinctly sums up a broadly shared idea about what design is.

Pevsner's dictum that 'the term architecture applies only to buildings designed with a view to aesthetic appeal' ${ }^{5}$ reminds us of design goals, such 
as those associated with style and composition, which are inherently much more difficult to articulate with precision. Relative to such goals, design decisions and design evaluation depend on the exercise of judgement. Rather than deal with aesthetic appeal in all its aspects, here we deal with a more limited question: how does a designer think about a building so as to make it more likely that visitors and users will come to see it as the result of deliberate design effort? We do not claim that this question is always raised, less so that it always is given prominence. But the question goes to the heart of certain kinds of design conceptualisation that are fundamental to architecture.

We propose that a designer who is sensitive to this question thinks about the building's logical form. Here, we have in mind Susanne Langer's proposition that logical form is about structure, or the way in which a thing is constructed. ${ }^{6}$ She draws attention to the fact that 'putting things together' is not only a matter of physical but also of logical assembly. Thus, the particular kinds of conceptualisation that we discuss in this paper pertain precisely to the logic of how a design is put together, so that its relevant properties appear to derive from a compositional principle. To clarify what is at stake we need to address the ideas of configuration and configurational meaning.

Hillier used an ingenious example to define configuration as relations taking into account other relations (Fig. 1). ${ }^{7}$ Two rooms, A and B, have a door between them, as in Figure 1.1. Depending on
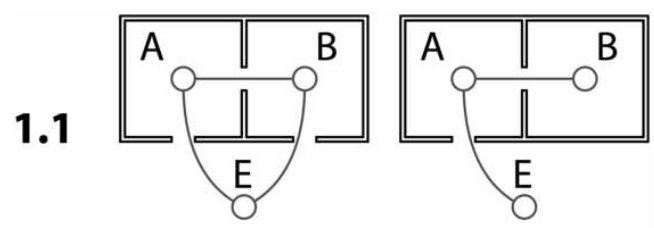

Figure 1. Configuration defined as relations taking into account other relations (drawn by the authors).
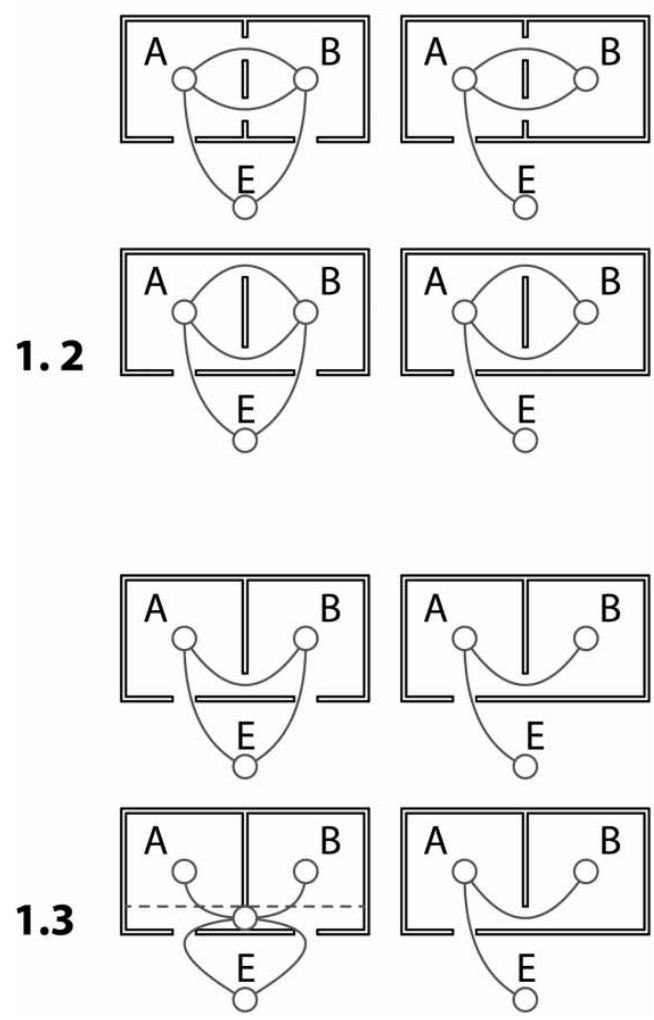
whether each of the two rooms or only one of them has a door to the exterior, their direct relationship, while physically the same, is qualitatively changed. If both rooms have a door to the exterior, their relationship is symmetrical. If only room $A$ has such a door, then their relationship is asymmetrical, with room A controlling access to room B. The particular example used to define configuration is closely linked to social function and meaning. In the asymmetrical relationship, room $B$ is more 'private' relative to room A, perhaps a bedroom; room A might lend itself to function as a day room or living room. Also note that the power of the example partly derives from the fact that elements and relationships are taken to be discrete, obvious, and amenable to representation using simple graphs.

Suppose that instead of having one door between rooms $A$ and $B$ we place two doors, as in the top row of Figure 1.2. Hillier's argument regarding the alternative possible relations to the exterior would remain intact. Now suppose that the doors are pushed to the extremities of the internal wall, as in the second row of Figure 1.2. The graph remains unchanged. However, by virtue of maintaining the continuity of the outer boundary, the new geometry lends itself to the interpretation that a single large space is being subdivided. By contrast, in the top line of Figure 1.2, the most likely interpretation is that the two rooms are independently defined and brought together by addition. These interpretations do not change the graph representation of connections. Yet, they are about relations (room adjacency and connectivity) taking into account other relations (of addition or subdivision). What is at stake is the inferred logic of derivation. An architect who engages the issue might be looking for ways to induce the user or visitor into imaginatively 'reconstructing' such derivation, based on clues (such as the placement of the openings) offered by the design.

Now suppose that we keep a single connection between rooms $A$ and $B$, but take it right at the front, along the external wall. As shown in the first row of Figure 1.3, we could describe this arrangement by graphs identical in structure to Hillier's. However, in the case where each of the rooms $A$ and $B$ have a door to the outside, the new arrangement might suggest a 'circulation zone' along the front of the building, as shown in the second row of Figure 1.3, by virtue of the fact that we can move in one door and out the other without substantially penetrating the rooms. This interpretation is less convincing in the case where only room $A$ has a door to the exterior. The difference is also deeply configurational, and concerns the emergence of a third space by virtue of the disposition of connections between the original two spaces and the exterior. In this case what is at stake is our way of parsing the given design into elements and relationships. Depending on such parsing, and the reading of the affordances of the design, different behavioural and furniture arrangements might be implied.

Accordingly, we propose a modified definition of configuration. Configuration is the entailment of a set of co-present relationships embedded in a design that allows us to read a logic into their co-presence. Through the exercise of imaginative attention, the entailment of relationships might be assessed from the point of view of functional implications, or from the point of view of logical derivation, or from the point of view of parsing the design into new 
elements and relationships, so as to read new affordances relative to habitation and space use. The question then becomes how configurational meaning, or the understanding of these multiple chains of entailment, is conceptualised during design, so that the products of design are imbued by a logical form. ${ }^{8}$

Below we examine what is at stake through the examination of examples. Prior to presenting the examples, we must address some methodological problems that derive from the nature of configurations: The entailment of relationships within a configuration can always be richer than a particular discursive description or representation of the configuration may capture. Thus, understanding the process of designing and the product being designed requires a continuous trade between reading conceptual content in drawings and considering discursive or diagrammatic clarifications of what is at stake.

\section{The problem of reading conceptual content in design}

Architectural design thinking is intrinsically documented in drawings, even as words, diagrams, numbers, or charts are necessary to explain design decisions, direct attention to significant characteristics of the design, or evaluate it against a given set of criteria. The essential function of drawings is to represent the building. Representation is handled by the rules of geometrical projections, ranging from perspectives that come close to capturing the actual view of a building from a particular point, to orthogonal projections that maintain consistency of measurement in a chosen plane. In addition, drawings also feature notational conventions-thickness of lines, angles of picture plane, colors, and use of writing or graphical symbols. Insofar as a design is the outcome of thinking, however, drawings implicitly also document a way of thinking. Thus, we may distinguish between the main instrumental purpose and the broader symbolic functions of drawings. The instrumental purpose is to describe a design, usually in a way that can instruct those who will implement it. Their symbolic function encompasses the expression of a way of thinking about the particular design represented, or about architecture in general. ${ }^{9}$ The symbolic content of drawings, however, is not immediately apparent and cannot be deciphered according to simple notational conventions. By implication, architectural design thinking, as expressed in drawings, cannot easily be put into words.

To understand why this is so, it is useful to remember, again, the work of Susanne Langer. ${ }^{10}$ She drew a distinction between discursive and presentational symbolism. Discursive symbolism requires that ideas are ordered in sequence as in language, while presentational symbolism allows that ideas are presented all at once as in pictures. The fundamental difference between language and pictures, as Langer saw it, pertains to the way in which a symbolic composition becomes meaningful. Language has a vocabulary of words with defined meanings, a syntax that allows words to be composed in sequence, the possibility of defining the meaning of each word using other words, the possibility of using alternative words for the same meaning and the power to express general statements. ${ }^{11} \mathrm{~A}$ picture, on the other hand, has elements whose identity and reference cannot be defined outside the picture itself. The picture functions as a symbol 
only through the relationships sustained by elements within the total structure. Finally, a picture can convey generality only by explicit specification, whereas the meaning of words is inherently general. Langer's motive for drawing this distinction was to argue that both kinds of symbolism partake in our conceptualisation of the world and are subject to logical formulation of how things are put together. She, like many others, opposed the view that systematic thinking is exclusively expressed in language or other discursive forms of symbolism.

Architecture, of course, is unlike pictures or language. Like pictures, it works presentationally, by articulating elements and relationships between elements into an integral whole. But, to complicate matters further, unlike pictures, it is not available 'all at once' and can only be comprehended through movement and through an active effort to construct a mental image of the building as a whole. $^{12}$ Drawings are a designer's means to engage with such non-discursive content in architecture. However, as we have discussed, architecture is subject to design criteria that are stated discursively ahead of design. It is also subject to evaluation during and after design, in terms of performance expectations that are also stated discursively. Compositional and stylistic principles, or design generators may also find discursive expressions. In order to relate discursive and non-discursive meanings, architects often use diagrams, sometimes drawn before and sometimes drawn after the design is developed. ${ }^{13}$ In such cases, diagrams often appear to have the force of a generative idea-a concept-presenting the building as a built instance of a stated proposition. But unless such diagrams can be inferred from the formal character of the building, the proposition they describe will remain opaque to visitors or users. It follows that if a designer intends users or visitors to become aware of propositional content, their design needs to meet an additional burden-to ensure that its conceptual content is inferable in its form, that is, in its presentational aspect. Thus, the tension between presentational and discursive modes of symbolisation reaches into the core of architectural design thinking. It may even be its defining character.

In what follows, and given our interest in how conceptual ideas are inferable from design, we do not give priority to the question 'how does a design concept, expressed in words or in diagrams and words, get developed into a design' but rather to the complementary question 'how does the production of drawings during design support emergent conceptualisations'. In short, we focus on the two-way traffic between Langer's discursive and presentation modes of thinking during design.

Quite naturally, conceptualisation is a primary consideration in the earliest stages of design, when designers come to terms with a design problem. This, however, should not lead to the conclusion that conceptualisation occurs in the earlier stages only or that design is a one-way process from abstraction to concretion. ${ }^{14}$ Of course, in the earlier stages of design, architects explore how design knowledge already acquired, including experience with building types, relevant precedents and formal rules, might help come to terms with the problem at hand. ${ }^{15}$ Conceptualisation, however, can extend late in the design process, as 
shown by many researchers. ${ }^{16}$ As design progresses, the role of the architectural drawing is not merely to provide evidence for deductive reasoning (does the emerging form fit the adopted concept?), but to provide an empirical basis for abductive inferences too (what concept could be inferred from emerging design?). ${ }^{17}$ We are thinking particularly of abduction as described by Peirce: ${ }^{18}$ properties present in the design or striven towards in the course of elaboration of the design, are construed as derivable from a conceptual form abduced from reflection on the drawings. ${ }^{19}$

The difficulty with describing the conceptual content of a design lies precisely in the tensions between discursive and presentational forms. Words help us see things in a design or think about a design in a particular way, but do not replace it. A critical function of words is to point to the relevant properties of the design which are present in the drawings. ${ }^{20}$ The reason why words are necessary is that the conceptual content of drawings cannot be interpreted based on notational conventions. To recognise the abstract ideas that might be inherent to a design we must often look at drawings in non-notational terms and focus on what the drawing directly depicts (for example, particular shapes) or what the drawing exemplifies (for example, the consequences of applying compositional rules such as symmetry, axiality, layering or overlap). The fact that drawings can be looked at from such different points of view has led some scholars to adapt the analytical terminology developed by Goodman ${ }^{21}$ to their study: Goel, ${ }^{22}$ for example, suggests that earlier design phases are characterised by forms of drawing that incorporate ambiguity and are open to multiple interpretations because lines could 'mean' different things; design development is marked by drawings that become increasingly precise and disciplined by specific representational conventions.

We will examine two distinct examples, one documented in the history of architecture, and the other constructed artificially for the purposes of argument. We discuss a particular aspect of conceptualisation, namely the clarification not of what the design is, but what kind of thing it is, or what it should be 'seen as'. The first example is the case of Louis Kahn working on the Unitarian Church Project in Rochester and reconceptualising the design late in its development. Reconceptualisation did not involve notable departures from an original organising schema stated in a diagram. Still, it fundamentally altered Kahn's own understanding of the project and helped settle important design decisions. As these decisions got settled so the project is presented to our own understanding not as a mere realisation of the abstract organising schema-one of many that were explored within the design process itself or one of the even greater number that we could imagine-but as a specific configurational concept that was not prescribed by the organising schema.

The fact that Kahn reflected back on the project and offered to reconstruct his design thinking, helps interpret the presentational conceptualisation implicit in his drawings and sketches with some authority. Authority is exercised in directing our attention to specific design issues, in leading us to see particular things in the design as we are invited to understand the design in a particular way. 
Authority is also exercised in framing the design exploration within a 'design space', that is, a particular sub-set of the many alternatives that we could imagine deriving from the initial diagram.

The second example is computational so that all generative and interpretative authority is explicitly invested in procedures. All possible designs arising from a given set of rules are listed as members of a design world. The design world is then analysed from the point of view of alternative criteria, each applied automatically. As a result, the world is partitioned into different sub-sets, according to the new descriptions of the designs. The sub-sets stand as extensional definitions of new concepts, concepts that were not stated in the original rules that produced the world of designs. The rules are then re-written to incorporate explicitly, and control for, the new descriptions. The aim of the exercise is to distinguish between producing a new design and producing explicit new distinctions or a new understanding of what is possible and what holds interest within a design world. Thus, the second example serves as a formal and explicit model of the cognitive processes that may be implicit in the first. ${ }^{23}$

\section{Kahn's design of the Unitarian Church in Rochester, 1959-1961}

Among the buildings of the second part of the twentieth century whose design is reasonably well documented, the Unitarian Church at Rochester is of particular interest (Fig. 2). The different solutions worked out by Louis Kahn between 1959 and 1961 could be interpreted as variations of an archetypical compositional intent: centralised plan with centripetal organisation of programme. Successive drawings document the adaptation of such intent to the context of design and the interaction between the architect and the client. A more careful analysis of the successive drawings produced during the 'second phase' 24 leads us to a different interpretation. Despite the resemblance of plans to each other, particularly from the point of view of functional organisation, the evolution of the design is marked by a fairly sharp discontinuity of architectural conceptualisation. A first phase where composition is handled as an additive agglomeration of discrete units around a central core gives way to a second phase where the scheme is characterised by continuous bounding surfaces peripherally layered around a centre. The syntactic discontinuity between the two phases has important implications for the manner in which the design becomes experientially and perceptually present as a configuration. $^{25}$

Figure 2.1 shows the initial design proposal, prepared in 1959. The geometry of the plan consists of an outer square, a circle, a dodecagon and an inner square, all concentric. These shapes function as a frame for arranging the programme. The assembly hall is placed in the middle, surrounded by an ambulatory, which separates it from the rest of the building. A peripheral corridor along the outer edge of the ambulatory leads to all other rooms. The programme itself comprises four basic elements: library, teaching and assembly rooms, administrative offices, and support spaces. Kahn uses geometry very characteristically in order to express the programme. Thus, he seems to think that the organisation of the programme along the perimeter, with emphasis on teaching, defines an envelope for the 


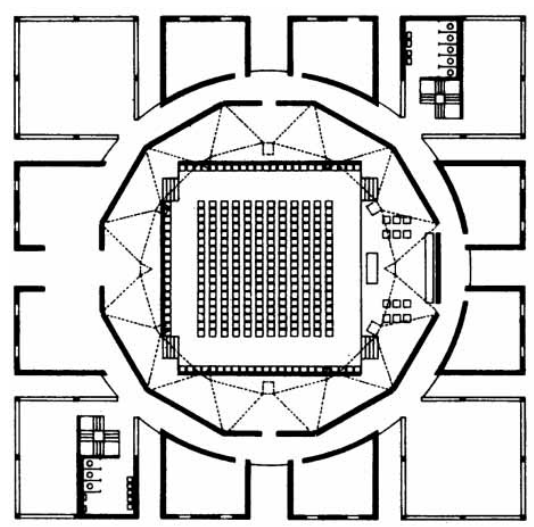

2.1

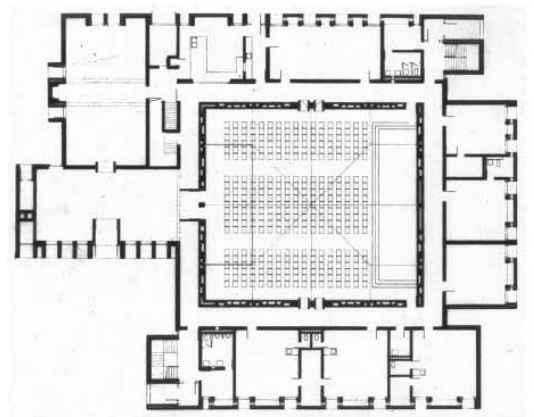

2.4
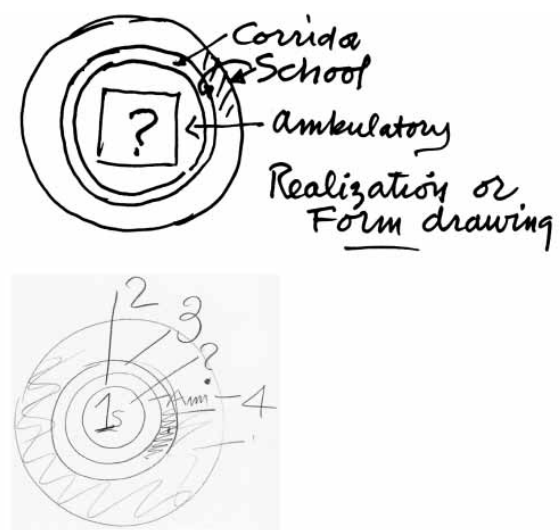

2.2

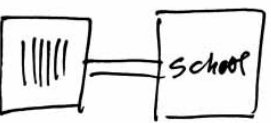

No!

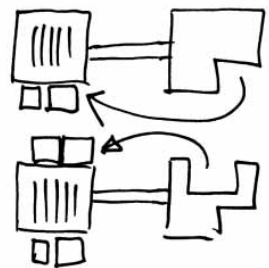

Tex of the validity of

Design resulling from circumstantial de mands
Figure 2. Selections from drawings and sketches for the First Unitarian Church and School Project,

Rochester (Louis I. Kahn Collection, University of

Pennsylvania and

Pennsylvania Historical and Museum

Commission, (C) 1977): 2.1, plan at the end of the first design phase, December, 1959 (detail of Ronner 87 UNC 12-

17): 2.2, sketch published in Kahn, 1961 (detail of Ronner 87 UNC 12-17); 2.3, earlier version of the organisational schema, copy of diagram drawn by Kahn during the first meeting with clients, July, 1959 (detail of 030.I.A.525.1); 2.4, plan from the second design phase, January, 1961, version adopted for construction (030.IV. B.525.1.15); 2.5, the sequence of sketches documenting the transformation from a two-block scheme desired by the clients into Kahn's preferred concentric scheme, sketch dawn by Kahn in the course of his interview with 
Perspecta (Kahn, 1961; detail of Ronner 87 UNC 12-17). sanctuary contained within. A certain tension between the educational component of the programme and the sanctuary is expressed in the mediating role of the circle and the dodecagon placed between the two squares. A similar tension is supported by the sketch published in Perspecta ${ }^{26}$ (Fig. 2.2), accompanying an interview with Kahn. The sketch should not be read merely as an affirmation of a centralised organisational principle. In this regard, it is different from another similar sketch found in Kahn's archives at the University of Pennsylvania (Fig. 2.3). The sketch shown in Perspecta depicts not only a topological principle, but also a particular geometric realisation that engenders the tension and dialogue between square and circle.

The plan of the building as built is presented in Figure 2.4. There are two obvious differences relative to the first proposal that was presented in December, 1959. First, the new solution is more economical. Second, the functional programme is arranged in wings, with the library near the entrance, and support spaces, administration and teaching/assembly spaces along successive sides moving clockwise. Kahn explains that the client initially envisaged a building divided into two volumes, one housing the sanctuary and the other school, offices and support spaces such as the kitchen. We could hypothesise that the client had in mind the organisation of a similar Unitarian Church designed by Frank Lloyd Wright thirty-two years earlier (Fig. 3). In the sketches shown in Figure 2.5 Kahn explained to his interviewer for the Perspecta articles how at a meeting with the committee overseeing the design, he was able to convince the clients of the superiority of his concentric scheme. The sketches illustrate how he began with a hypothetical bi-polar plan desired by the clients, and then led the committee to see that some support activities would work better if relocated back to the sanctuary. As the committee members gradually assented to his moves, one by one, the entire programme of the ancillary was shifted to a square ring around the sanctuary. ${ }^{27}$ If, however, we read the sketch in Figure 2.5 as an expression of evolving thinking, we see a pronounced difference between it and the sketches in figures 2.2 and 2.3. In Figure 2.5, the programme is broken into partial units that have a distinctive presence around the church. Similarly, in Figure 2.4, the wings accommodate an additive organisation by distinct functional zones. In the other two sketches the perimeter of the scheme does not result from an agglomeration but is an integral shape.

Can we speak of adherence to the same design concept when we compare the initial and the final proposals (Fig. 4)? To a degree, the answer is positive. As Kahn himself asserts, he succeeded in bringing back the sanctuary to the centre. But this is not sufficient to explain the subsequent modifications of the scheme tracked in figures 4.1-4.4, all of which precede the final design shown in Figure 2.4. The basic programmatic elements were well in place by the time the scheme in Figure 4.1 was drawn up. Although there are some differences, for example those pertaining to the shaping of the library and the office wing, the drawings seem subject to the same organising logic. In reality, by Kahn's own account, the moment of formulation, the revelatory moment at which he felt that the 


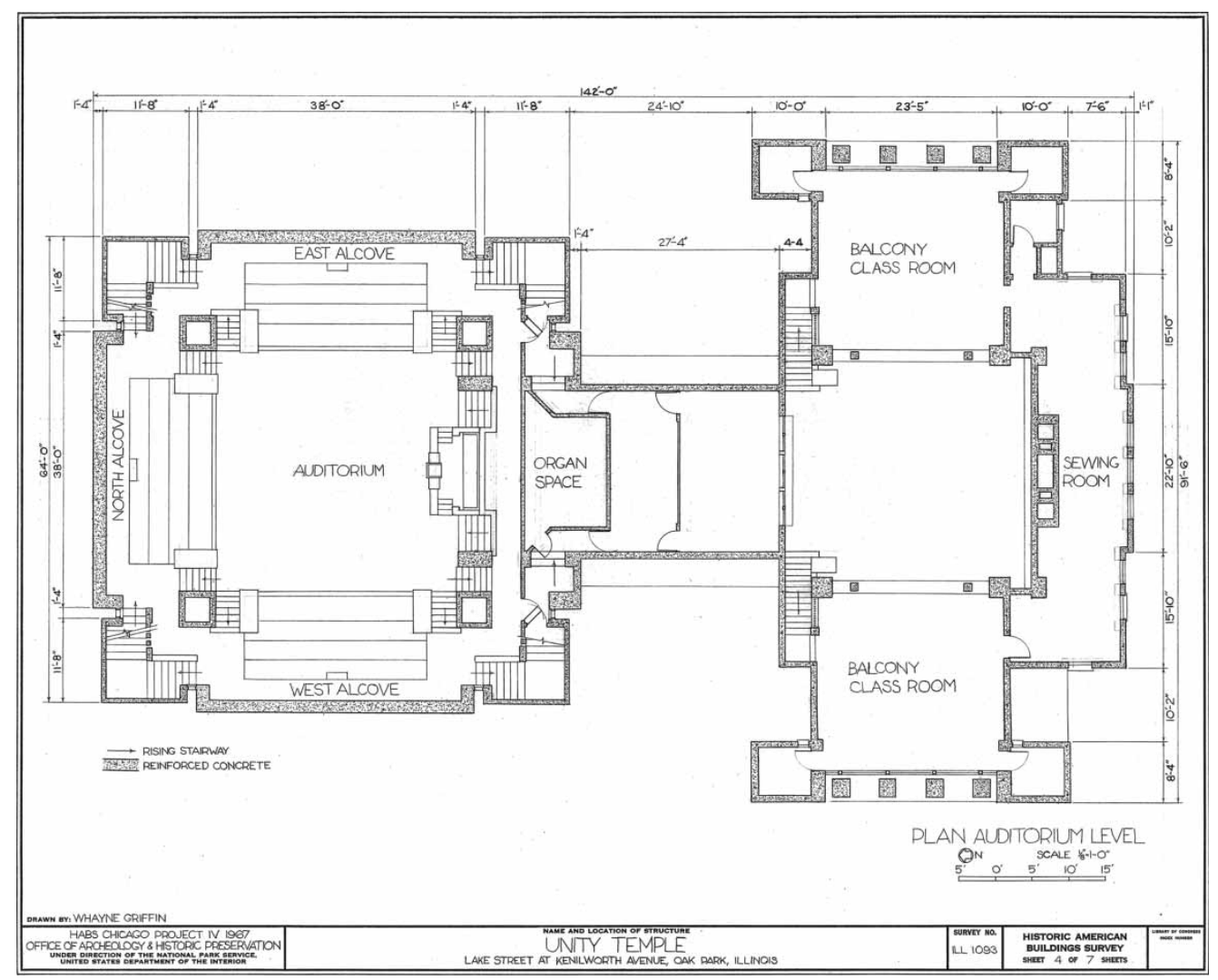

design settled in place, occurred between the schemes presented in figures 4.2 and 4.3 .

The difference between these schemes becomes clearer if we also consider the respective elevations, shown in figures 4.5 and 4.6 . Figure 4.5 shows that Kahn first conceived of the building in terms of repeated units of standardised modules. The units correspond to main rooms. The modules that repeat themselves correspond to room and window widths. In Figure 4.6, on the other hand, Kahn has moved on to consider a continuously folding wall with recesses. The window widths are repeated at less regular intervals. Repetition now seems secondary relative to the perceived continuity of the wall. This is a fundamental change relative to the underlying architectural conceptualisation. From
Figure 3. Unity Temple and House, Oak Park IL, designed by Frank Lloyd Wright, 1906:

auditorium level plan showing the sanctuary and the school housed in their own distinct blocks (credit: Historic American Buildings Survey, HABS ILL, 16OAKPA, 3- [sheet 4 of 7] —Unity Temple, 875 Lake Street, Oak Park, Cook County, IL; HABS is a programme of the National Park Service of the United States Government established for the purpose of documenting historic places-records consist of measured drawings, archival photographs and written material. 
Figure 4. Further selections from drawings and sketches for the First Unitarian Church and School Project, Rochester (all images from Louis I. Kahn Collection, University of Pennsylvania and Pennsylvania Historical and Museum

Commission, (C) 1977 [KC], unless noted otherwise): 4.1-4.4, successive versions of the ground-level plan presented during the second design phase from June, 1960 to January, 1961 (KC 030. IV.B.525.1.8-detail; 030. IV.B.525.1.16-inverted; 030.IV.B.525.1.17-

stitched; 030.IV.

A.525.5.6); 4.5, North and East elevations of the Church corresponding to the plan in Figure 4.1 (KC 030.IV.B.525.1.9); 4.6,

North elevation corresponding to the plan shown in Figure 4.4 (Digital Image (C) The Museum of Modern Art/ Licensed by SCALA / Art Resource, NY); 4.7, sequence of sketches from the Perspecta interview documenting
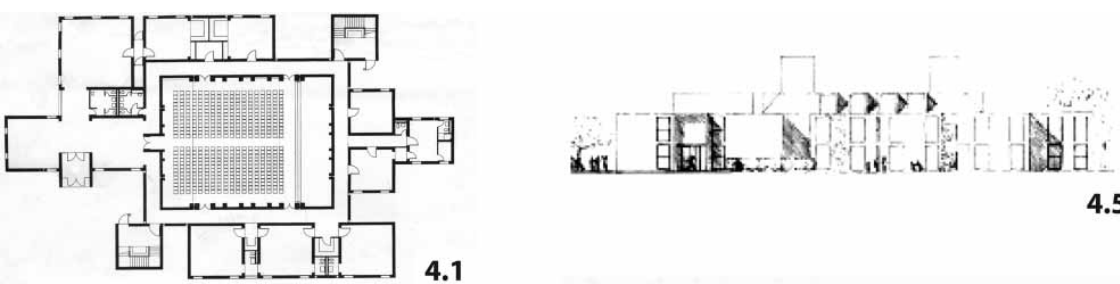

4.5

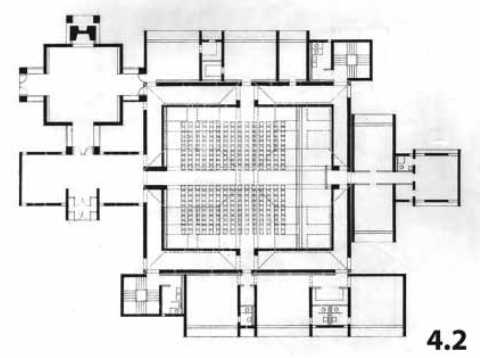

$$
\text { 1919 }
$$

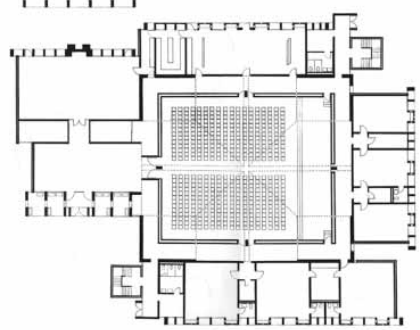

4.3

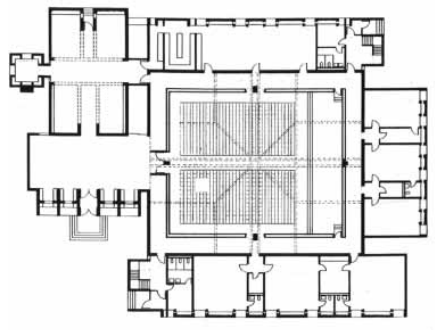

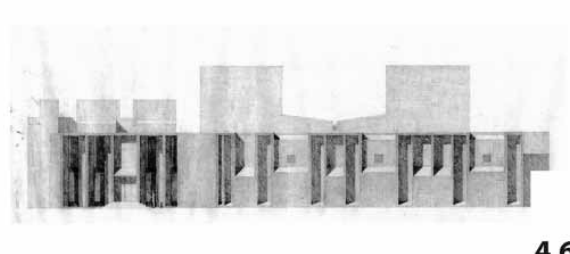

4.6

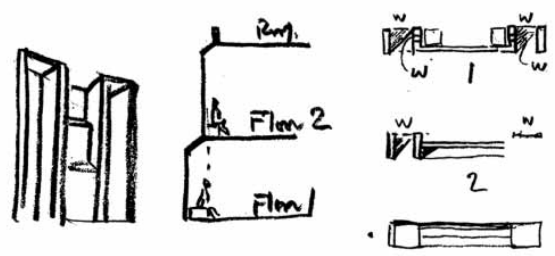

4.7
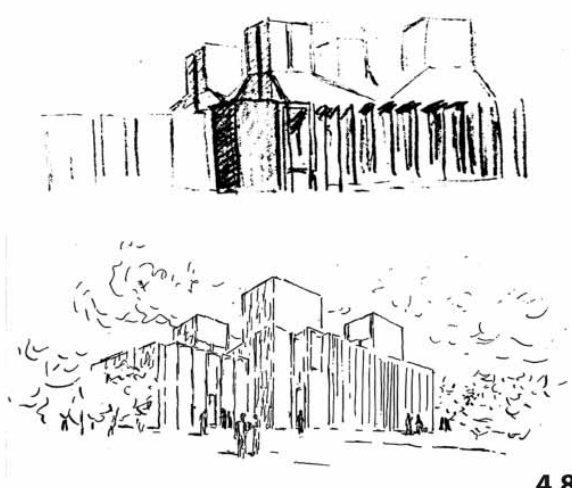
the syntactic logic of multiple units aggregated around a centre, we move to a syntactic logic of arranging interior spaces between a folding outer enclosure and an inner core. The fact that the organisation of the plan does not significantly differ across the two proposals is important. The difference we highlight is configurational. It does not bear on the organisation of functions but rather on the manner in which this organisation is presented to perception. The change in perceived organisation is important because it allows the building to develop a coherent image. Kahn himself spoke about an emergent gothic sensitivity. ${ }^{28}$ With this visual image comes a fundamental shift in the architect's conception of the building. The design shifts from a building that is conceived as a centripetal plurality to a building that is perceived as a unity. We thus come to appreciate another transformation that occurs between the plans shown in figures 4.3 and 4.4. The horizontal axis that worked to hold together the building as a whole, going through the sanctuary, is removed. In the new design the sanctuary is conceptually seen as a self-contained space, precisely because the integrating element is no longer the axis but the surrounding wall.

The shift in conceptualisation, however, does not seem to have emerged at one go in such clear terms. Kahn introduces the change talking about one particular element of the composition, the window. Using drawings that refer to older buildings, he notes that windows opened into deep walls, or windows surrounded by architectural elements that imbue them with depth, are better at controlling the quality of light. This is because incoming light is reflected and glare is controlled. He then proceeds to discuss how introducing folds in the wall allows the design of seats inside the window recess, or how, depending upon the depth of the recess, a different relationship is established to interior space: Figure 4.7.

The careful development of a partial elementthe window-leads to an overall shift in the latent conceptualisation of the overall design. This is in turn recorded in sketches that show the building volumetrically, emphasising the outer wall as the architecturally primary element, according to the intensity and dynamic of the lines drawn. We are, therefore, dealing with a process of gradual and retrospective clarification of conceptual transformations. The transformation from figures 4.2 to 4.3 is carried through drawings that reveal the interplay of abstraction and presentational symbolisation. Kahn uses drawings not just to verify the geometry of the emergent forms or to communicate information about shape to others, but also to glean from them those properties of the actual building that identify it as a particular kind of configuration.

The reconstruction of the logic of a particular design process and design outcome offered here resonates with some prevailing ideas in design studies. The problem that is resolved by Kahn's revelation of the properties of the deep folded wall is not quite an ill-defined problem. As discussed in the literature, ${ }^{29}$ the ill-defined problem is one whose solution parameters are not precisely specified. In this case the functional organisation of the successive plans remained more or less untouched. ${ }^{30}$ The problem that was resolved here was that of finding a configuration-a logical form -on the basis of which further design decisions the development of the motif of 'boxed-in' windows, triggered by Kahn's reflections on the quality of light in the thick reveals of classical windows; this development occurred between the schemes illustrated in figures 4.2 and 4.3 , and marks a moment of conceptual change occurring late within the design development phase (KC Ronner 77 UNC 33-35); 4.8, perspectival sketches in Kahn's hand exploring the visual quality of the façades featuring the boxed-in window motif ( $\mathrm{KC}$ Ronner 77 UNC 30 and 31). 
could be taken. In general terms this is consistent with the pattern of successive problem definitions, that characterises reflective practice according to Schön, ${ }^{31}$ as well as with the idea that the abstract spaces of problem definition and design solutions co-evolve during design. ${ }^{32}$ The idea of the undulating perimeter wall sustains relationships with a multitude of other ideas: it addresses the issue of the quality of light, it alleviates the tensions arising from the prior desire to fit different parts of the programme into an additive pattern of repeated modular units, it complies with the idea of centralised planning that was accepted throughout. Thus, it would most likely emerge as a 'good design idea', a 'critical move' had we had data that would have allowed us to represent the process in terms of linkography, ${ }^{33}$ where a good idea is defined according to the density of connections to moves that come before and after.

None of these statements, however, get to the core of conceptualisation within the design process, as expressed in the drawings we have available. Conceptualisation is about the way in which ideas fit together as an holistic configurational proposition. The coherence that Goldschmidt identifies as a generic aim of design ${ }^{34}$ is achieved through a process of abduction. That is to say, desirable properties are retrospectively made to appear as deriving from the application of an abductively inferred set of parsimonious generative principles. In order to understand more fully the process of abduction we have to track the conceptual shift in drawings which describe the design in all its relevant elaboration, delineation as well as shadow effects, rhythm of vertical elements as well as continuity of undulation-in Goodman's terms, in drawings which are referentially replete. ${ }^{35}$ Thus, we cannot agree that the 'conceptual' is in evidence primarily in representations which do not refer to physical attributes as argued by Goldschmidt. ${ }^{36}$ The more overtly 'conceptual diagram' used by Kahn has remained relatively stable, as the conceptualisation of the design problem and the design aim have changed.

To state that each of the designs complies with the abstract conceptual diagram, or can be construed as being 'derived' from it through a process of 'elaboration in depth' does not help to explain why Kahn produced so many variations, or to identify the critical differences discussed above. Furthermore, the words used by Khan underscore the incremental manner in which the configurational shift came about and gradually became rationalised: 'There's a true beginning of it (the meaning associated with windows) in this plan [Fig. 4.3]. And it became really well expressed in this plan when the windows-instead of being so very prevalent as in this plan-became much more carefully considered [Fig. 4.4] ... It's a play really of wall and variety in the getting of various conditions around the windows which caused me to make these changes. ${ }^{137}$ It is only by considering discursive and presentational symbolisation together than we can reconstruct the conceptual shift in design configuration, the configurational meaning that Kahn points to by talking about a transition from classicist to gothic sensitivity.

\section{Closing the circle of production, description and conceptualisation within design: a theoretical experiment}

A computational experiment is constructed, to provide a formal and entirely discursive account of 
shifts in conceptualising what kind of thing is being formulated during design. In order to generate a complete design world, we use a shape grammar, as defined by Stiny. ${ }^{38}$ Shape grammars are constructed to generate families of shapes by successively applying shape substitution rules (where you see a specified shape you may replace it by another specified shape) to an original shape taken as a starting point-the assumption is that a given shape is understood not simply as a figure with a specific geometry, but as an encoding of a computational process applied to other shapes. In combination with a schema for assigning semantic content to the shapes (labels such as walls, windows, rooms and so on), ${ }^{39}$ the generated shapes can be treated as designs, with the grammar encapsulating a general generative approach, say, a style, or an idiom. Thus, shape grammars function as discursive symbolisations of design generators. Rules are explicit; it is possible to decide whether a design is well formed according to the rules and the initial shape available; and, in controlled conditions, it is possible exhaustively to apply the rules to an initial shape and generate all possible designs. We subsequently apply space syntax analysis to the design world generated by the rules, in order to describe functional properties of the resulting designs, including the way they might respond to particular programmatic requirements and the way they become available to the understanding of a subject situated inside them based on their perceptual affordances. Bridging between shape grammars and space syntax is, however, incidental to our argument. Our aim is to model the interaction between design generators

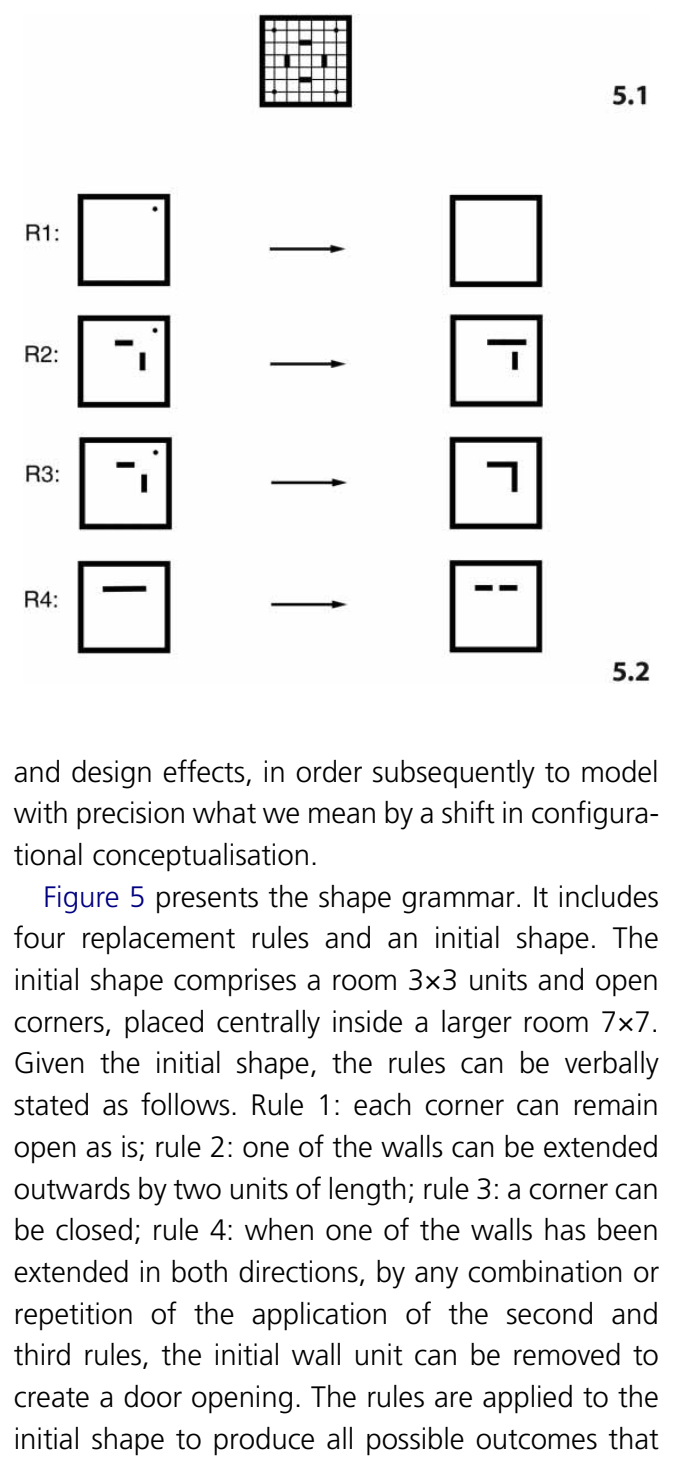

Figure 5. A shape grammar with an initial shape, 5.1 and four replacement rules, 5.2 (source: the authors). 
Configurational meaning and conceptual shifts in design John Peponis, Sonit Bafna, Saleem Mokbel Dahabreh, Fehmi Dogan

Figure 6. All possible shapes obtained from the exhaustive

application of the rules applied to the initial shape in Figure 5

(source: the authors).

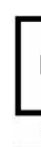

I

$\frac{1}{2}$

$$
\text { L }
$$

\section{L}

$$
\text { 픈 }
$$$$
1
$$
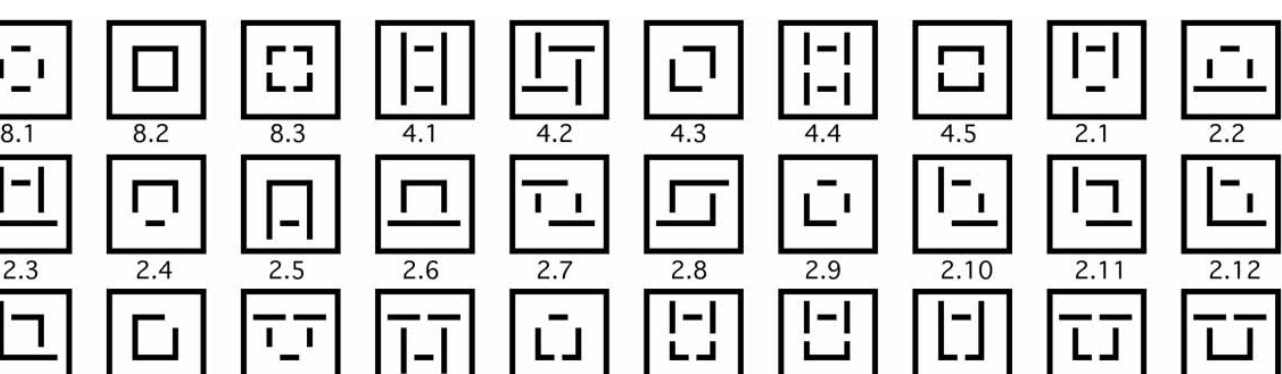

2.13

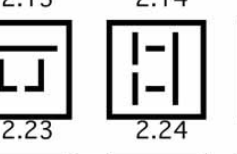

$-1$

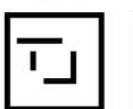

1.2
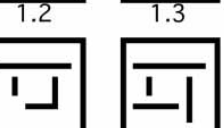

LI
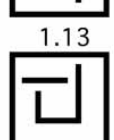

1.22

$\frac{\mathbf{L}}{1.32}$

$\frac{\Gamma 7}{1.42}$

Г?

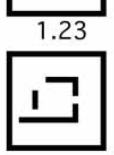

1.33

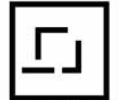

1.43

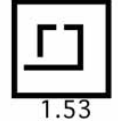

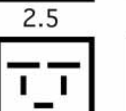
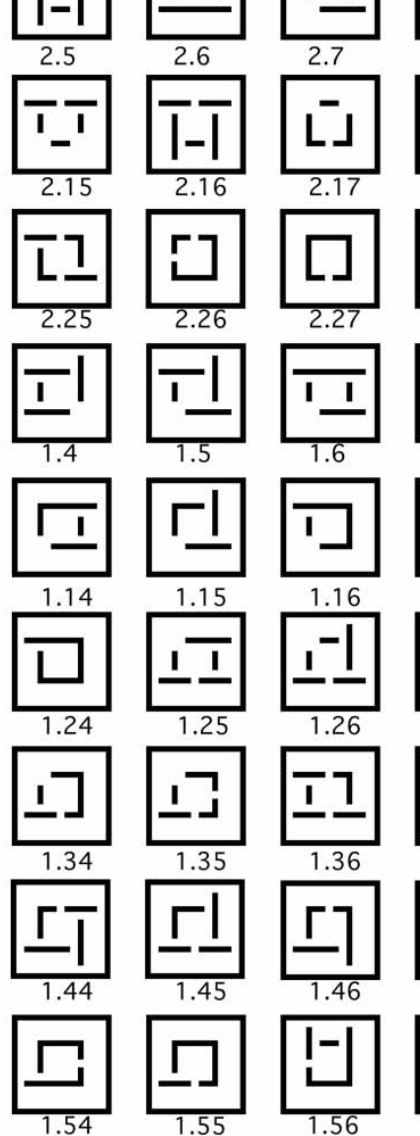

1.24
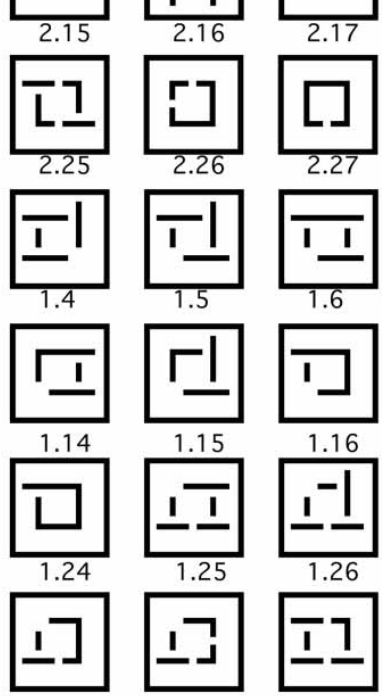

1.26
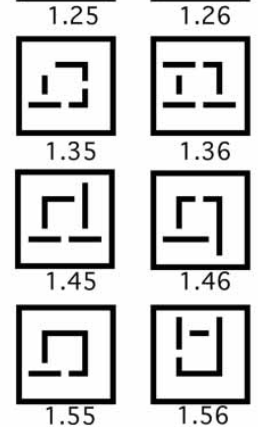
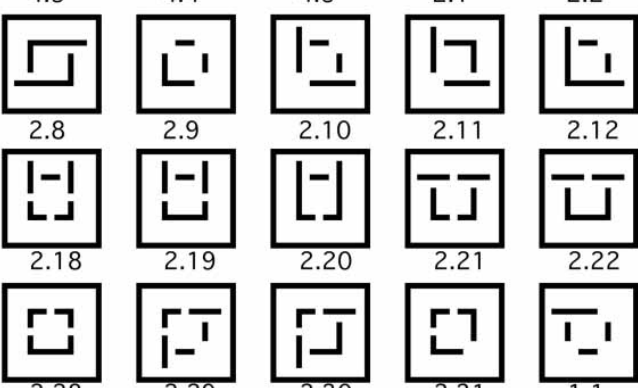

(1)
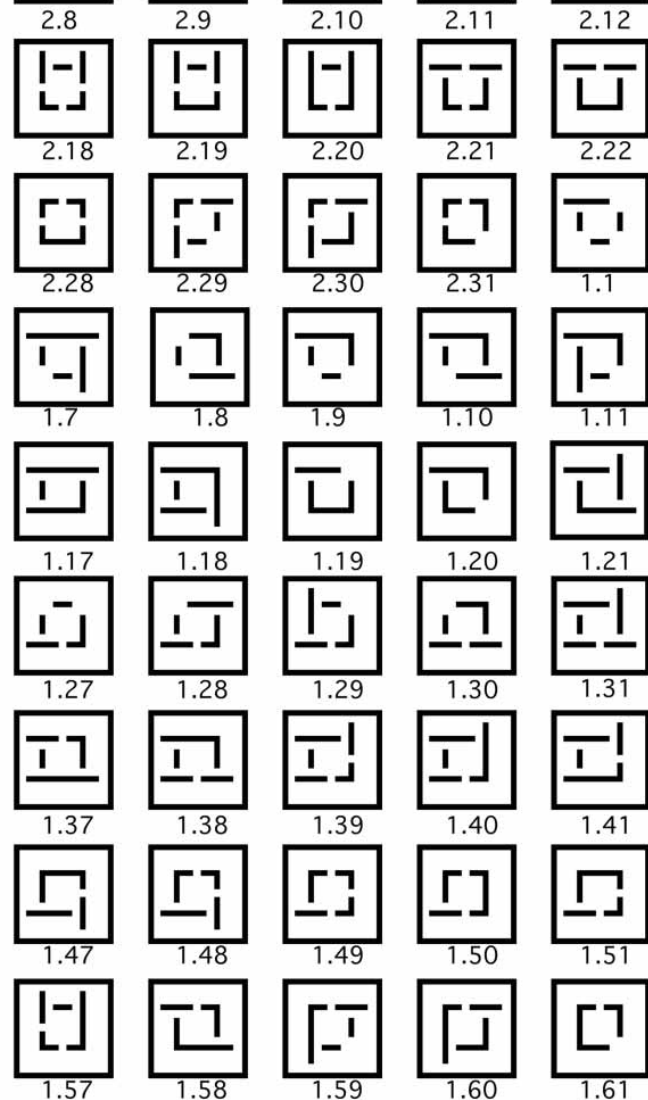

2.21

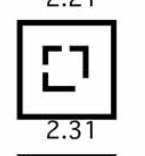

2.22
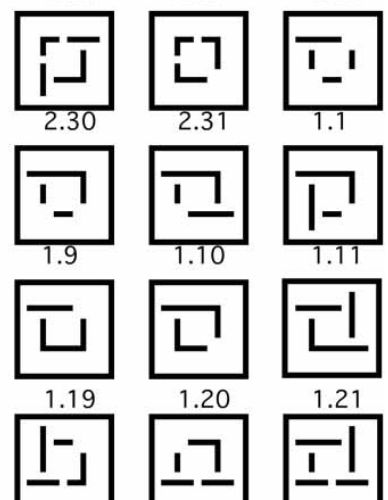

1.1
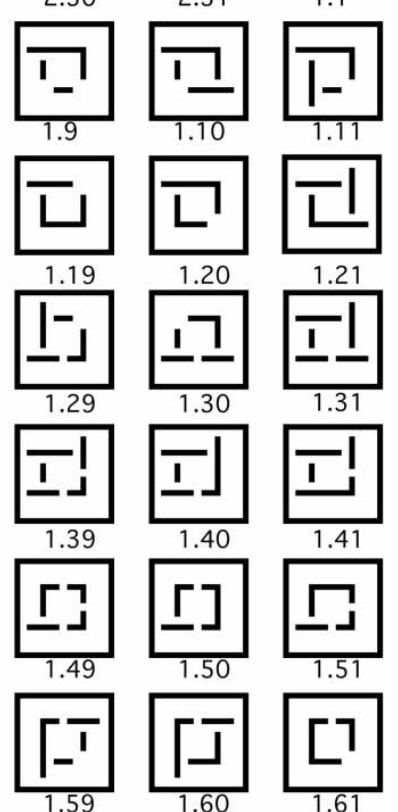

$$
1.31
$$

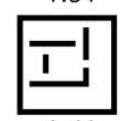

1.41
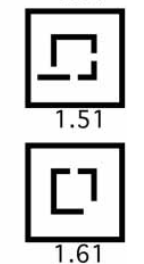
are distinct after taking into account isometric transformations (translation, reflection, rotation). As in shape grammar conventions, dot notations are used to control the applicability of rules over the various sub-shapes of the initial shape, and constrain the various sequences of development. ${ }^{40}$ The auxiliary use of dots also enables the differentiation between terminal design states and intermediate states that allow further operations. Terminal states do not include any auxiliary dots.

The catalogue of all possible designs from the exhaustive application of the rules is presented in Figure 6. Good aesthetic fortune leads to exactly 100 designs. We note that the rules and their outcomes were initially proposed in order to examine the logically and perceptually distinct ways in which four walls on a rectangular grid can define an inner square space. ${ }^{41}$ This is an exercise resembling the earliest ones given to entering students in many schools of architecture. Figure 6 includes a classical room with four doors (6-8.3), a room in Mies's spin-wheel idiom (6-4.2) with all walls extending outward beyond the inner space, a room in Schindler's idiom (6-8.1), that is with corners open, and a room in Rietveld's idiom (6-2.13), that is, one with an diagonal thrust. Thus, the shape grammar describes what else is possible when these paradigmatic kinds of inner rooms are generated as part of a design world in one particular way.

Generative rules are of course not equivalent to rules of reading or evaluating a set of designs. Suppose that we ask: which design lends itself to interpretation as an exhibition space that can accommodate the maximum number of paintings into an egalitarian arrangement which offers com- parable access to all? This requirement could be translated into seeking the design which maximises wall length and also the connections between resulting convex spaces. ${ }^{42}$ Figure $6-4.2$ best responds to this criterion of evaluation: to keep this paper brief we do not present the calculation, but the reader can easily verify the result. Suppose on the other hand that we are looking for an exhibition layout which allows one exhibit to stand out as holding particular value. If we also suppose that an exhibit that is not immediately exposed but discovered at the termination of a path will appear to have greater value, then we would evaluate designs according to depth measured by transitions across the boundaries of convex spaces. ${ }^{43}$ Using this criterion, figures 6-2.5, 6-2.27 and 6-1.24 emerge as best solutions (the calculations are not presented, also in the interests of brevity). Thus, the catalogue can be taken through the sieve of diverse evaluation criteria, to highlight various member designs.

Allowing great but legitimate simplification, this is the manner in which Simon would understand the relationship between the heuristic exploration of possibilities and their evaluation leading to design choices. ${ }^{44}$ The problem with this approach is that the criteria used for evaluation and design choice do not necessarily interact with the intrinsic logic of the generative rules. Thus, the essence of compositional logic is absent from the model of design process. This is a problem for two reasons. The first is that, unlike our example here, it is not always possible to generate all possible designs in order to find the ones best satisfying our criteria-the designer needs to proceed by having an intuition about probable functional outcomes of specific generative 
Figure 7. Partitioning of a given shape into convex sub-shapes such that a constant set of end-points and corners is visible from within each sub-shape: Figure 7.1 shows the corners and end-points that have a direct line of sight from a chosen root point; Figure 7.2 shows the sub-division of the given shape into all its constituent sub-shapes; Figure 7.3 shows the graphic representation of centrality relative to visual changes. Distance is counted by the minimum number of sub-shapes that are crossed to go from each sub-shape to all others; lighter shades indicate sub-shapes with high centrality and darker shades those with low centrality (source: the authors).
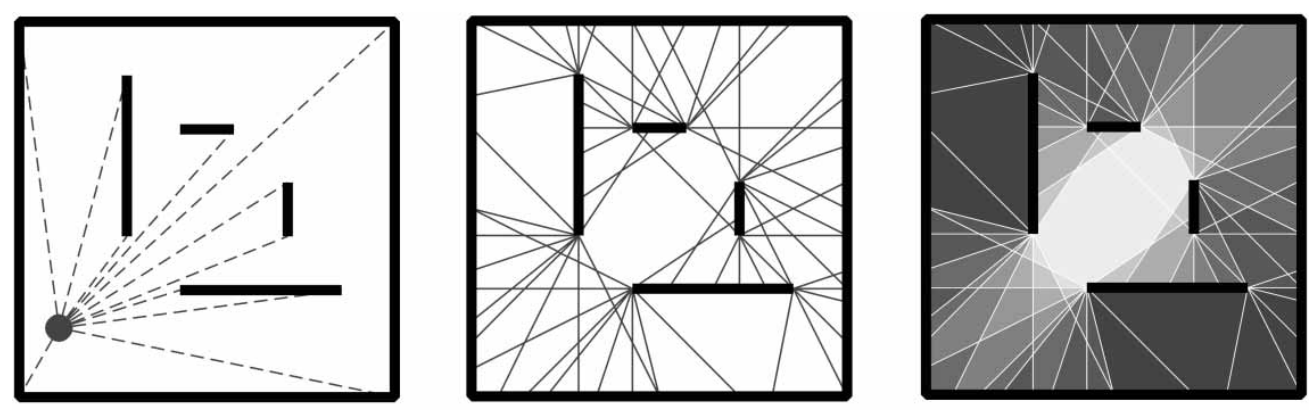

7.1

7.2

7.3 moves. Second, designers, as in the Kahn case above, are not interested merely in functional requirements, but also in issues of perception, specifically, in the qualities of coherence and feeling associated with the forms that emerge as generative rules are applied.

Given the initial intention that produced the generative rules, namely to examine the different ways in which four modular walls on a rectangular grid can define an inner space, the designs are analysed to reveal their perceptual structure from the point of view of a situated observer. ${ }^{45}$ The method can be briefly outlined as follows: the extensions of extendible visibility diagonals are drawn, for all pairs of covisible wall endpoints or corners; the convex space partition resulting from the intersection of these lines is recognised. We notice that while remaining in the same convex space, a situated observer is exposed to the same sub-set of endpoints or corners, in other words she is placed in a condition of informational stability relative to shape. We also notice that when the observer crosses a line, at least one endpoint or corner is added or subtracted from the field of vision. We subsequently compute the centrality of each convex space relative to the available perceptual changes, according to the minimum number of other convex spaces that mediate the path to all other positions in the plan. Centrality values are then graphically represented by colouring the plans. In this way we can easily observe which areas are syntactically nearer the complete set of visual thresholds implied by the design, as explored by a situated observer. The analytical process is explained in Figure 7 . The first drawing indicates that we are interested to characterise a randomly selected position based on the endpoints and corners that are visible. The second drawing shows the subdivision of the plan according to the threshold of visibility of such endpoints or corners. The third drawing shows the graphic representation of centrality relative to visual changes.

How then might the interior quality of the inner space surrounded by the four walls be perceived and understood in the light of the analysis? In the 
Figure 8. Patterns of relative centrality in all the shapes obtained in Figure 6. The shapes are partitioned as described in Figure 7 and their sub-shapes coloured according their relative centrality: the range goes from lighter shades (high centrality) to darker shades (low centrality) passing through intermediate colours (source: the authors). 
Figure 9. The fourteen shapes of Figure 7, in which the most central sub-shapes extend or are entirely outside the central walls (source: the authors).

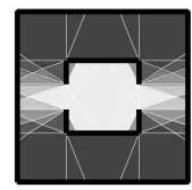

4.5

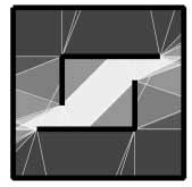

2.08

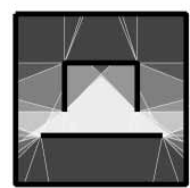

2.06

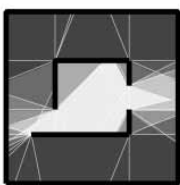

1.54

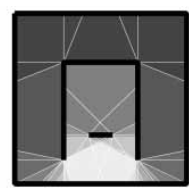

2.5

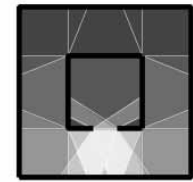

2.27

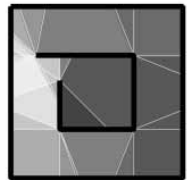

1.24

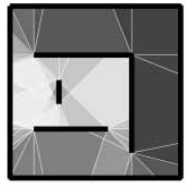

1.18

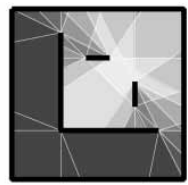

2.12

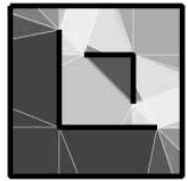

2.13

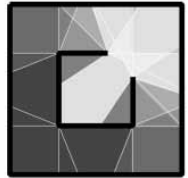

2.14

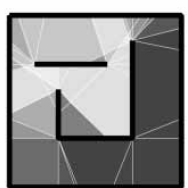

1.23

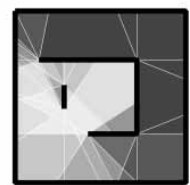

1.16

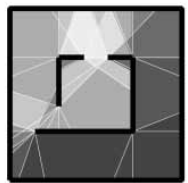

1.53 
clear majority of the designs in the catalogue, the centre of the shape lies between these walls, as we would intuitively expect. This is evident in Figure 8 which presents the analysis of all one hundred plans. The inner space is also the central space from the point of view of visual information about shape. However, there are fourteen exceptions, shown in Figure 9 where they are arranged in distinct columns. In the four designs of the first column, 9-4.5, 9-2.8, 9-2.6, 9-1.54, the centre extends from the inner space out towards the perimeter, thus defining a passage. In the designs of the second column, 9-2.5, 9-2.27, 9-1.24 the centre lies between the inner space and the perimeter, thus defining a threshold. In the designs of the fourth column, 9-2.12, 9-2.13, 9-2.14, 9-1.23, $9-1.16,9-1.53$, the centre encompasses the inner space and part of the perimeter, forming an emergent square which is defined in parts by the inner walls and in parts by the walls of the perimeter. The single design of the third column, 9-1.18 is a hybrid and has properties similar to those of both adjoining columns. Thus, while the catalogue was generated by a single desire to create an inner space, the member designs are significantly differentiated as to their perceptual implications, more particularly the relationship between the inner space and the structure of centrality relative to visual information. The differentiation between geometric and syntactic centrality noted here is similar to that which has been observed by Psarra in her study of actual museum buildings and architectural designs. ${ }^{46}$

The concept of emergence has been defined in two notable ways. ${ }^{47}$ In the context of shape grammars, the word 'emergence' describes a situation where the spatial relationship between two or more shapes (on the left side of a substitution rule) produces additional (emerging) new sub-shapes similar to the initial shapes (on the right side of the substitution rule) $)^{\prime 48}$ For example, two initial triangles can be placed into relationships that allow us to retrieve descriptions of any number between 2 and 8 triangular sub-shapes. ${ }^{49}$ In the context of the theory of space syntax, ${ }^{50}$ 'emergence' describes the complex spatial structure that arises from the successive local application of simple generative rules. The drawings of the fourth column of Figure 9 hold special interest because they combine the two kinds of emergence. Indeed, syntactic emergence leads to the retrieval of a description of emergent shapes. The emerging pattern of syntactic centrality relative to visual information (syntactic emergence) leads us to see a square $5 \times 5$ that results from the relationship of the two initial squares $3 \times 3$ and $7 \times 7$ (shape emergence).

The analysis of the designs shown in Figure 8 indicates that the results of the compositional rules are richer than the rules themselves. In very simplified form, we have an example of discovery within design. We retrospectively recognise the morphological implications of the generative rules that were not explicitly prefigured in the rules themselves, even as they are linked to the intention associated with the creation of the rule. But how can we register the emergent conditions in the generative rules? Or, to ask the question in more concrete terms, how can we reformulate the generative rules so as to discriminate between, and deliberately control, the subsets of designs that they will produce? Figure 10 presents four shape grammars. The first produces the 
Figure 10. Four alternative shape grammars. The first produces the same set of shapes obtained in Figure 6. The others produce a selected subset of those spaces. Note the increased number of rules in $\mathrm{G} 1$ as compared to the grammar presented in Figure 5 (source: the authors).
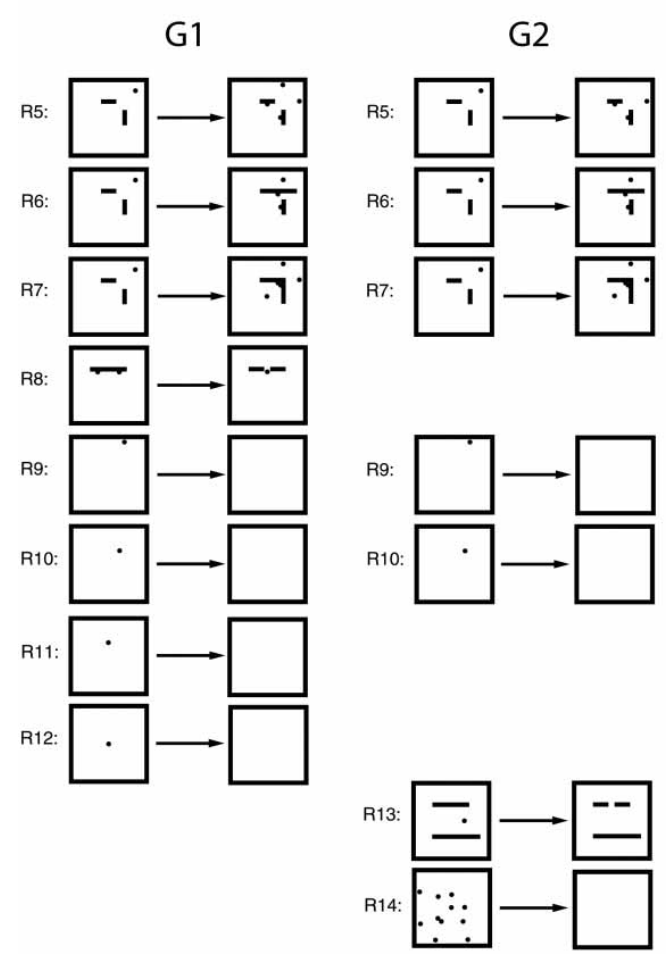
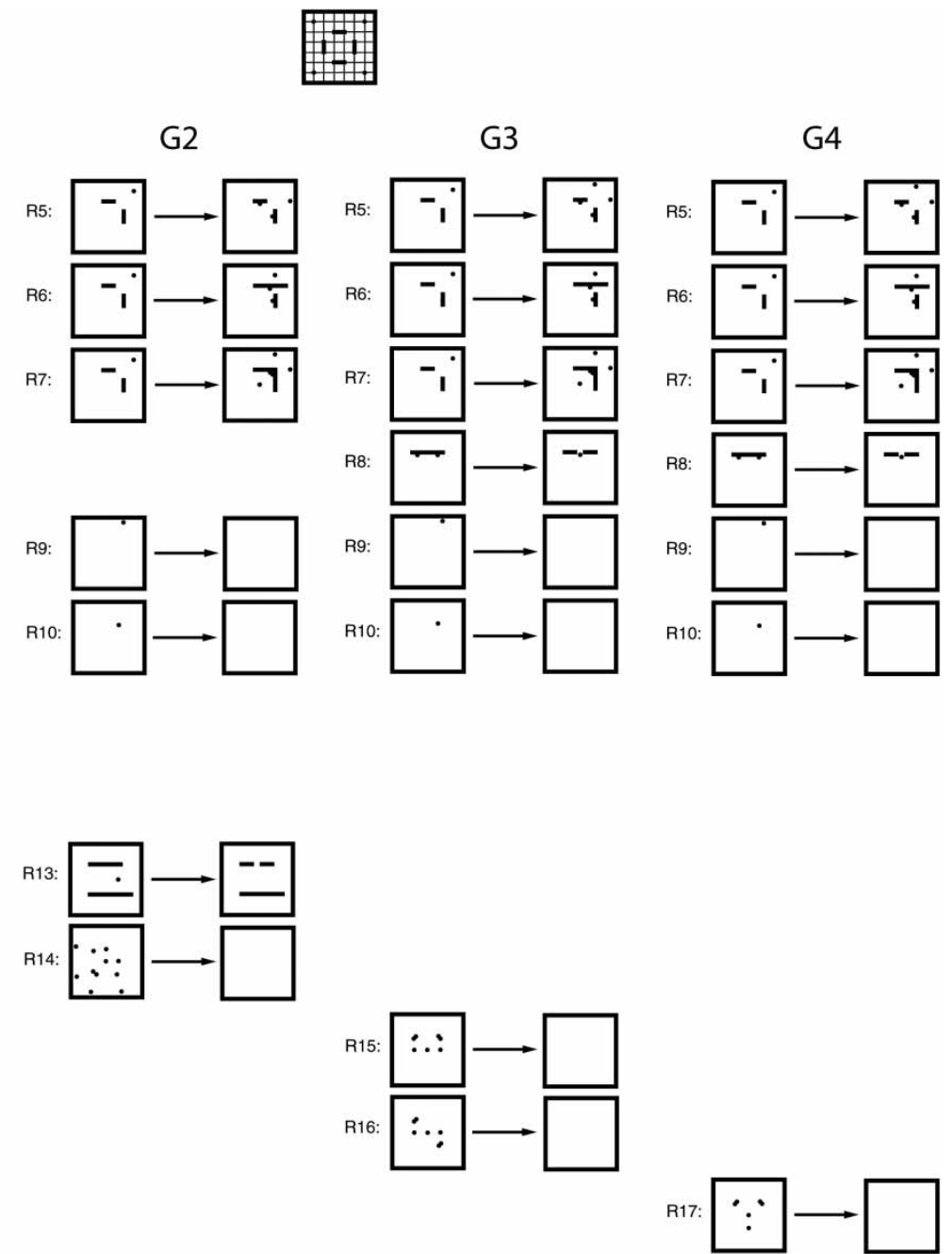
complete set of designs offered in Figure 6. The second produces only the designs of the third and fourth columns of Figure 9. The third produces the designs of the first column. The last produces the designs of the second column.

The difference between the initial grammar of Figure 5 and the first grammar of Figure 10 bears on the use of different patterns of auxiliary marks. These are introduced in order to notate spatial relationships that are linked with the emerging structure of centrality relative to visual information. In the interests of economy we do not reproduce the analysis that led to the identification of these relationships and to the corresponding notations. Readers can check for themselves that the grammars offered, when exhaustively applied to the initial shape, produce the original universe of designs and the particular design subsets mentioned above.

With the use of additional auxiliary notations, grammar G1 (Figure 10) encompasses double the number of rules compared to the original grammar (Figure 5). The grammar has thus become less laconic. What is gained is the ability to write the other three grammars (G2-G4) by means of a different deployment of the auxiliary notations. Only one of the new grammars requires the use of a new substitution rule that presupposes the identification of a different sub-shape for its application. In short, the redundancy of the first new grammar allows the more elegant formulation of the other three.

From the point of view of the usual approach to shape grammars, the argument deployed through Figure 10 may appear to be paradoxical. Usually, the transformation of grammars is aimed at producing new designs. ${ }^{51}$ Why then bother to write new grammars that produce the same set of designs, or different subsets of it? The answer to this question is that the new grammars shown in Figure 10 are not aimed at enriching the set of designs but rather at registering new knowledge about it. Configurational meaning is expressed in the writing of new rules of derivation that incorporate distinctions arrived at by analysis of the original design world. The possibility of a new description of any shape, based on a new set of rules, acts as the computational equivalent of a new understanding. Design does not advance only when the object designed is being changed. Design also advances when the manner of thinking about the object changes. Once explicitly registered, the interplay between geometric and syntactic centrality 'discovered' could be transferred to different shapes and relationships. In this regard, Psarra's analysis of actual museums, mentioned above, is particularly relevant.

\section{The conceptualisation of configuration and design judgement}

The historical example and the theoretical experiment entail two kinds of conceptual shifts regarding configuration. First, we have changes in the relationships that hold interest, which lead to changes in the description of the design: Kahn became interested in the design of window recesses and the option of an undulating wall. In the theoretical experiment we declared an interest in the perceptual structure and affordances of designs. Second, we have changes in the rules of generation or derivation of form: Kahn implicitly switched from an additive centripetal and modular pattern of composition to a pattern of subdivision between continuous inner and outer 
boundaries. In the theoretical example, new grammars were created to allow the controlled production of sub-sets of the original design world, according to the perceptual structures engendered by the individual designs. The two kinds of conceptual shift are associated with changes in configurational reading. It so happens that in each case, conceptual shifts are also overlaid upon a foundation of invariance. With Kahn, what stays invariant is the intention to adhere to a centralised plan. In the experiment, what stays constant is the schema of a room placed in the middle of another. More important, in each case, visual work with drawings was an indispensable step towards re-conceptualisation. Kahn produced multiple sketches of the new design principle for the outer wall, as well as several new plans with the new arrangement. In the case of the experiment, the emergent interplay between geometric and syntactic centrality did not become apparent until the outcomes of analysis were visualised and visually explored.

Thus, what the historical example and the theoretical experiment have in common helps to highlight the import of conceptual shifts during design. It also helps explain why conceptual shifts can occur beyond the early stages of the design process. Conceptualisation is not limited to an original formulation of the design problem as a whole, or to a subsequent reformulation of the problem as a whole based on a new understanding of design parameters. Rather, it also encompasses new layers of configurational definition and articulation, which only emerge once the outline of the problem and the design approach have been decided and a domain of formal exploration has been etched out.
The differences between the historical example and the theoretical experiment are as important as the similarities. In the experiment, very simple generative rules are applied to generate a design world. In actual design such a creation of a universe of alternatives is usually not possible because the generators of form are multiple and the possible combinations almost always very many. By implication, exploration proceeds within a narrower sub-set of possibilities based on design judgement and informed by experience, knowledge of precedent or intuitions that may remain tacit. In the experiment, the interrogation of the design world is based on a small set of criteria, mostly limited to the perceptual effects of designs. In actual design this type of criteria would normally remain tacit, as more pressing programmatic and performance considerations (for example, required size, types and relationships of spaces, services, and environmental conditions) would take priority. In the experiment, the evaluation of the perceptual effects of designs is given computational precision through a fairly extended analytical effort. In actual design this would not often be the case. Judgement rather than explicit evaluation would come into play.

From the point of view of configurational meaning, differences come down to the fact that in the experiment 'generation' (the initial shape grammar), 'description' (the analysis of perceptual structure) and 'discrimination' (the identification of different relationships between shape and syntactic centrality) are marked as distinct procedural steps leading to an abductive cognitive outcome: the final production of new generative rules (the final shape grammars); in actual design, the abductive leap, where it occurs, is 
about configurations, generative principles and criteria of judgement that are formulated in close interaction, bridging all the time between presentational and discursive modes of symbolisation. The fact that design addresses configurations, in the way we defined them here, and the complex interplay between the principles of parsing, functionality and derivation inherent to configurations, explain why the tension between presentational and discursive symbolisation is so germane to architectural thinking. The theoretical example we constructed serves to clarify with analytical precision what goes on when we manipulate configurations, when we imaginatively read a logic of entailment between relations that take into account other relations. The historical example serves as a reminder of how the abductive leap towards the conceptualisation of logical form remains incompletely formulated in practice, at least in terms of discursive symbolisation. Hence the capacity of configurations to activate imaginative attention.

\section{Acknowledgments}

This paper has been significantly improved thanks to the insightful comments by two anonymous reviewers. Discussions with the following people have been important to this work: Daniel Koch, Maria Kokkinou, Andreas Kourkoulas, Iris Lycourioti, Nancy Nercessian, Sophia Psarra, Mahbub Rashid, Vaso Trova.

\section{Notes and references}

1. H. A. Simon, The sciences of the artificial (Cambridge, Mass., The MIT Press, 1996).

2. The idea that artists bring their own aims into the production of a work is central in: M. Baxandall, Patterns of intention: on the historical explanation of pictures (New Haven, CT, Yale University Press, 1985).

3. See, for example, M. Girouard, Life in the English country house (New Haven, CT, Yale University Press, 1980); R. Evans, 'Figures, Doors and Passages', in Translations from drawings to building (Cambridge, Mass., The MIT Press, 1997), pp. 54-91; J. Hanson, Decoding homes and houses (Cambridge, Cambridge University Press, 1998).

4. See, for example, F. Duffy, The changing workplace (London, Phaidon Press, 1992); F. Duffy, K. Powell, The new office (London, Conrad Octopus, 1997); or, much more recently, C. Congdon, D. Flynn, M. Redman, 'Balancing "me" and "we"', Harvard Business Review, vol. 92 (2014), pp. 50-7.

5. N. Pevsner, An outline of European architecture (Harmondsworth, Middlesex, Penguin Books, 1963).

6. S. K. Langer, An introduction to symbolic logic (New York, Dover, 1967), p. 24: 'The bridge that connects all the various meanings of form-from geometric form to the form of ritual etiquette-is the notion of structure. The logical form of a thing is the way that the thing is constructed, the way it is put together. Anything that has a definite form is constructed in a definite way.'

7. B. Hillier, Space is the Machine (Cambridge, Cambridge University Press, 1996), p. 34.

8. The issues raised here are obviously more intensely present in designs that do not comply with already familiar morphological or functional types, designs that formulate new configurational principles with respect to functional and perceptual affordances or with respect to logical structure. This is discussed at greater length in J. Peponis, 'Formulation', The Journal of Architecture, vol. 10, 2 (2005), pp. 119-133.

9. The symbolic functions of drawings are discussed in: S. Bafna, 'How architectural drawings work - and what that implies for the role of representation in archi- 
tecture', The Journal of Architecture, vol. 13, 5 (2008), pp. 535-564. Here, we use the term 'symbolic function' in the manner of Cassirer and Langer: E. Cassirer, The philosophy of symbolic forms: mythical thought (New Haven, Yale University Press, 1955); The philosophy of symbolic forms: language (New Haven, Yale University Press, 1955); The philosophy of symbolic forms: the phenomenology of knowledge (New Haven, Yale University Press, 1957); S. K. Langer, Philosophy in a new key (Cambridge, Mass., Harvard University Press, 1942).

10. Ibid.

11. We describe these points using Langer's own language (An introduction to symbolic logic, op. cit., pp. 75-94), noting that some of Langer's explanations of how language acquires meanings has since been modified by further work in analytical philosophy. Still at a broad level, her insights remain essentially correct, and her distinctions more pertinent to our purpose. Similarly, the distinction between discursive and presentational forms was given a logically more precise treatment in Nelson Goodman's Languages of Art (Indianapolis, Hackett, 1976), and its practical implications teased out by others: for instance, in the much-quoted Larkin and Simon, 'Why is a diagram (sometimes) worth a thousand words?', Cognitive Science, vol. 11 (1987), pp. 65-99-but for our purposes, the essential points in Langer suffice.

12. As is clearly discussed in P. Frankl, Principles of architectural history (Cambridge, Mass., The MIT Press, 1973; original German edition 1914). This simple fact is also recognised by many architects who, like Le Corbusier, look at plans in terms of the embodied movement they engender: see, for instance, Le Corbusier, Toward an Architecture (Los Angeles, Getty Research Institute, 2007)

13. Sometimes, the interpretation of a diagram into a design is presented in systematic steps, as in the work of Eisenman: P. Eisenman, Diagram Diaries (New York, Universe Publishing, 1999).

14. The idea that conceptualisation is limited to early design stages is recognised as the conventional model of design and subjected to criticism for limitations in: N. F. M. Roozenburg, N. Cross, 'Models of the design process: integrating across the disciplines', Design Studies, vol. 12 (1991), pp. 215-20; and also, from a point of view that resonates with ours, in $\mathrm{S}$. Psarra, W. Forster, 'Drawing in Process-The Creation of Architectural Concepts in the Studio', Proceedings of 'Drawing Across Boundaries' International Conference, Loughborough School of Art and Design, Loughborough, UK (1988): (http://www.lboro.ac.uk/ microsites/sota/tracey/journal/dab/1998/PDF/Psarra_ Forster-TRACEY-Journal-DAB-1998.pdf). Nevertheless, many studies in design cognition proceed on the assumption that conceptualisation occurs mostly in the earlier stages of design and that design thinking is a process of elaboration moving from abstraction to concretion. See, for example, G. Goldschmidt, 'Capturing indeterminism: representation in the design problem space', Design Studies, vol. 18 (1997), pp. 441-445; T. Purcell, J. S. Gero, 'Drawings and the design process', Design Studies, vol. 9 (1998), pp. 389-430; R. Oxman, R. M. Oxman, 'Refinement and adaptation in design cognition', Design Studies, 13 (1992), pp. 117-134. The last is of particular interest to this paper because it specifically refers to Kahn as an architect whose design process can be understood as a process of refinement of a generalised schema.

15. The reliance of design on mental pre-structures was emphasised in early articles such as, B. Hillier, A. Leaman, 'How is design possible', Journal of Architectural Research, vol. 3 (1974), pp. 4-11 and A. Colquhoun, 'Typology and design method', in Essays in architectural criticism: Modern architecture and historical change (Cambridge, Mass., The MIT 
Press, 1985), pp. 43-50. Of particular interest, in this context, is a reflection by a practising architect suggesting that design is often derived from a primary generator: J. Darke, 'The primary generator and the design process', Design Studies, vol. 1 (1979), pp. 36-44; the author recognises, however, that the primary generator may appear after extensive exploration of the problem. Her aim is to demonstrate that the primary generator is not 'derived' from the problem but introduced by the designer as an axiom to be tested through design elaboration.

16. For a clear statement of the interactions between drawing, seeing and conceptualising during design, see D. A. Schön, G. Wiggins, 'Kinds of seeing and their functions in designing', Design Studies, vol. 13 (1992), pp. 135-56; P. G. Rowe, Design thinking (Cambridge, Mass., The MIT Press, 1987).

17. This abductive reasoning should be taken as also being applicable to physical models, computer-created renderings and models, or any other representational or descriptive artefacts that may be used in the design process, even though in this paper we confine our remarks to drawings.

18. C. S. Peirce, 'Deduction, induction and hypothesis', The Popular Science Monthly, vol. 13 (1878), pp. 470-82.

19. In this we extend March's ideas about the functions of abduction in design: L. March, 'The logic of design and the question of value', in, L. March, ed., The Architecture of Form (Cambridge, Cambridge University Press, 1976). March emphasised the role of abduction in the earlier phase of design when the nature of the design problem and the range of possible design solutions are recognised. A pertinent analysis of the abductive work involved in conceptualisation through drawing is offered by Dogan and Nersessian in the analysis of Libeskind's diagrams for the Jewish Museum: F. Dogan, N. Nersessian, 'Conceptual dia- grams in creative architectural practice: the case of Daniel Libeskind's Jewish Museum', Architectural Research Quarterly, vol. 16 (2012), pp. 14-27.

20. For an insightful consideration of the limitations of using words to describe presentational forms like paintings, and how that leads to the distinctive character of critical language, see M. Baxandall, 'The language of art history', New Literary History, vol. 10 (Spring, 1979), pp. 453-465. Baxandall makes a particular note of the ostensive functioning of words in critical writing.

21. N. Goodman, Languages of art, op. cit.

22. V. Goel, Sketches of thought (Cambridge, Mass., The MIT Press, 1995).

23. The particular kinds of computation that are used are 'shape grammars' to generate designs and 'space syntax' to analyse them, but the forging of a dialogue between shape grammars and space syntax is an incidental benefit of an exercise directed towards a different aim.

24. We use the term 'second phase' to refer to the second scheme that Kahn developed between March, 1960 and January, 1961, after the first concentric scheme presented in December, 1959, was judged to be too large and expensive. For a reconstruction of the history of the project, see R. B. Williams, 'First Unitarian Church and School, Rochester', in, D. D. Brownlee, D. G. De Long, eds., Louis I. Kahn: In the realm of architecture (New York, Rizzoli, 1991), pp. 340-5. The sequence of floor plan drawings in this phase that we discuss are published in $\mathrm{H}$. Ronner, S. Jhaveri, eds., Louis I Kahn: Complete works 1935-1974 (Basel, Birkhäuser, 1987).

25. An earlier discussion of the evolution of the design of the Unitarian Church is offered in S. Bafna, 'Symbolic construction in non-discursive media: the design development of Kahn's Unitarian Church in Rochester', in, A. van Nes, ed., Space syntax: The fifth international symposium (Delft, T U Delft, 2005), pp. 265-278. 
26. See L. I. Kahn, 'Kahn', Perspecta, vol. 7 (1961), pp. 9-28.

27. Kahn's account seems to have oversimplified things. Williams claims that the actual shift from the bi-polar back to the concentric scheme happened, not in a single meeting, but gradually over the course of several months (R. B. Williams, 'First Unitarian Church and School, Rochester', op. cit., p. 344). But even if so, it is undeniable that the concentric organisation of the final plan was not simply the result of the working out of the initial diagrammatic schema, as it may appear, by a process of relaxing the overall shape of the outer ring into discrete and irregularly located programmatic elements.

28. L. I. Kahn, 'Kahn', Perspecta, op. cit., p. 17: 'LK: It is very Gothic isn't it? Does it bother you? I like it myself.'

29. H. A. Simon, The sciences of the artificial (Cambridge, Mass., The MIT Press, 1969) and 'The structure of illstructured problems', in Models of Scientific Discovery (Boston, D. Reidel Publishing Company, 1977), pp. 304-325.

30. Kahn did actually resolve two types of functional problems in the course of developing the plans of the second scheme-August Kommandant and he were able to work out a structural system for the roof of the main hall and of the library near the entrance, and he fine-tuned the design of the kitchen and its adjoining reception room. But even these functional solutions could only fall into place once the conceptual reorganisation was brought about.

31. D. A. Schön, The reflective practitioner (New York, Basic Books, 1983).

32. See K. Dorst, N. Cross, 'Creativity in the design process: co-evolution of problem solution', Design Studies, vol. 22 (2001), pp. 425-437; J. Poon, M. L. Maher, 'Co-evolution and emergence in design', Artificial Intelligence in Engineering, vol. 11 (1997), pp. 319327;M. L. Maher, 'A model of co-evolutionary design', Engineering with computers, vol. 16 (2000), pp. 195-208. The approaches represented by these articles, however, do not propose frameworks or methods for analysing drawings.

33. G. Goldschmidt, D. Tasta, 'How good are good ideas? Correlates of design creativity', Design Studies, 26 (2005), pp. 593-611.

34. G. Goldschmidt, 'Capturing indeterminism', op. cit.

35. N. Goodman, Languages of art, op. cit.

36. G. Goldschmidt, 'Capturing indeterminism', op. cit

37. L. I. Kahn, 'Kahn', Perspecta, op. cit., p.17

38. For an introductory presentation: G. Stiny, 'Introduction to shape and shape grammars', Environment and Planning B, vol. 7 (1980), pp. 343-351 and for a detailed treatment: G. Stiny, Shape (Cambridge, Mass., The MIT Press, 2006).

39. G. Stiny, 'A note on the description of designs', Environment and Planning B, vol. 8 (1981), pp. 257-267.

40. For an introduction to the basic conventions of shape grammars and some worked examples illustrating application to design, see T. Knight, Transformations in design (Cambridge, Cambridge University Press, 1994).

41. An early account of this exercise is presented in J. Peponis, 'The logic of space and the reasons of design', in, F. d. Holanda, L. Amorim, F. Dufaux, eds, 2nd International Space Syntax Symposium (Brasília, 1999), pp. 5.1-5.19.

42. A space is convex when any two points within it are joined by a line which does not cross the boundary. In terms of human function, convexity in principle guarantees that any number of people inside the space can all see each other. This would not be true in a non-convex space, such as an I-shaped room. In space syntax analysis, plans are often partitioned into an economic set of the largest possible convex spaces, as described in B. Hillier, J. Hanson, The social logic of space (Cambridge, Cambridge University Press, 1984). 
43. Ibid: : a typical kind of analysis associated with space syntax as originally introduced herein by Hillier and Hanson.

44. See H. A. Simon, The sciences of the artificial, op. cit. and 'The structure of ill-structured problems', op. cit.

45. The methodology for plan analysis from this point of view is introduced in J. Peponis, J. Wineman, M. Rashid, S. H. Kim, S. Bafna, 'On the description of shape and spatial configuration inside buildings: Convex partitions and their local properties', Environment and Planning B, vol. 24 (1997), pp. 761-781. The paper builds on the theory of space syntax introduced by B. Hillier, J. Hanson, The social logic of space, op. cit. The analytic methodologies of space syntax build, in turn, on the earlier introduction of graph theoretic analysis into architecture by L. March, J. P. Steadman in The geometry of environment: an introduction to spatial organization in design (London, RIBA Publications, 1971) and by J. P. Steadman in Architectural morphology (London, Pion Press, 1983). In essence, space syntax deploys graph theoretic representations of space in the interests of developing a theory of the social functions of architecture. Peponis et al., extend these methods to an analysis which is more sensitive to shape and the perceptual structure of layouts. A more recent discussion is offered in, M. Rashid, 'On space syntax as a configurational theory of architecture from a situated observer's viewpoint', Environment and Planning B, vol. 39 (2012), pp. 732-754; 'Mutual visibility of points in building plans', The Journal of Architecture, 16, 2 (2011), pp. 231-266.

46. See S. Psarra, Architecture and narrative: The formation of space and cultural meaning (London, Routledge, 2009). Psarra's analysis of Le Corbusier's design for the Tokyo Museum, as part of her chapter 'Tracing the Modern', raises very similar questions to those raised by the theoretical design world discussed here: she notes, in particular, that Le Corbusier's design 'dissociates the geometrical concept from the configuration of views and embodied experience' (p. 191).

47. While these two definitions of emergence are more relevant to our argument, a more extensive discussion of approaches to emergence in design studies, even though it misses syntactic emergence in as defined in Hillier's work, is offered in R. Oxman, 'The thinking eye: visual re-cognition in design emergence', Design Studies, vol. 23 (2002), pp. 135-164.

48. G. Stiny, 'Shape rules: closure, continuity, and emergence', Environment and Planning B, vol. 21 (1994), pp. s49-s78.

49. See a fully illustrated analysis in L. March, 'Babbage's miraculous computation revisited', Environment and Planning B, vol. 23 (1996), pp. 369-376.

50. The classic texts of space syntax are: $B$. Hillier, Space is the Machine, op. cit. and B. Hillier, J. Hanson, The social logic of space, op. cit. Both provide extensive discussions of emergence.

51. See T. Knight, Transformations in design, op. cit. 